\title{
Evaluasi dan Desain Ulang Unit Instalasi Pengolahan Air Limbah (IPAL) Industri Tekstil di Kota Surabaya Menggunakan Biofilter Tercelup Anaerobik-Aerobik
}

\author{
Achmad Muzakky, Nieke Karnaningroem, dan Mohammad Razif \\ Jurusan Teknik Lingkungan, Fakultas Teknik Sipil dan Perencanaan, \\ Institut Teknologi Sepuluh Nopember (ITS) \\ Jl. Arief Rahman Hakim, Surabaya 60111 Indonesia \\ e-mail: nieke@enviro.its.ac.id; razif@enviro.its.ac.id
}

\begin{abstract}
Abstrak-Perkembangan dunia fashion saat ini membuat permintaan produk tekstil meningkat. Industri tekstil $Z$ sebagai salah satu industri tekstil tua di Kota Surabaya berusaha untuk tetap bersaing dipangsa pasarnya dengan memproduksi berupa pakaian berwarna gelap. Peningkatan kegiatan produksi yang tidak diikuti dengan perubahan pada sistem pengolahan IPAL membuat perubahan pada karakteristik air limbah yang dikeluarkan oleh industri. Hal ini menyebabkan air yang dikeluarkan tidak memenuhi baku mutu. Sehingga diperlukan sebuah evaluasi dari setiap unit dan perencanaan ulang dari sistem IPAL. Evaluasi dilakukan dengan mengukur dimensi dari masing-masing unit IPAL eksisting, menganalisa sampel air limbah, dan membandingkannya dengan kriteria desain dari masing-masing unit. Perencanaan ulang dilakukan pada unit yang tidak berfungsi dengan baik. Biofilter tercelup anaerobikaerobik adalah salah satu teknologi yang dapat dijadikan sebagai alternatif karena memiliki banyak kelebihan dari aspek teknis dan finansial. Hasil evaluasi IPAL eksisting menunjukkan bahwa semua unit tidak memenuhi kriteria desain. Hal inilah yang menyebabkan air limbah yang dihasilkan tidak memenuhi baku mutu. Limbah yang dihasilkan IPAL eksisting adalah $52,05 \mathrm{mg} / \mathrm{L}$ TSS; 899,3 mg/L COD; 182,61 mg/L BOD; dan 31,85 PtCo warna. Rekomendasi berupa perencanaan ulang menggunakan biofilter tercelup anaerobik-aerobik menghasilkan limbah dengan kadar TSS, COD, BOD, dan warna secara berurutan adalah 15,93 mg/L; 29,05 mg/L; 2,99 mg/L; dan 2,63 PtCo dengan biaya investasi sebesar $\operatorname{Rp}$ 793.175.680.
\end{abstract}

Kata Kunci-Biofilter Tercelup Anaerobik-Aerobik, desain ulang, evaluasi IPAL, limbah cair tekstil

\section{PENDAHULUAN}

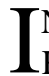
NDUSTRI tekstil $\mathrm{Z}$ adalah salah satu industri tekstil tua di Kota Surabaya yang telah lama bergerak dibidang perajutan dan pencelupan. Perkembangan dunia fashion yang global dan dinamis membuat permintaan produk pakaian dengan warna yang lebih variatif bertambah. Dampak dari perkembangan dan meningkatnya permintaan pasar membuat industri tekstil tersebut berusaha untuk tetap bersaing dipangsa pasarnya dengan memproduksi pakaian berwarna gelap. Dampak peningkatan kegiatan produksi industri tekstil membuat produk limbah yang dihasilkan bertambah dan mengalami perubahan karakteristik. Perencanaan IPAL pada awalnya didesain untuk mengolah air limbah tekstil dengan karakter limbah berwarna cerah tetapi akibat peningkatan dan perubahan karakteristik limbah yang dihasilkan, menyebabkan
IPAL tidak bekerja secara efektif. Mengetahui kurang efektifnya IPAL yang dimiliki, industri tekstil tersebut segera melakukan perbaikan pada sistem IPAL dengan penambahan unit berupa tanki aerasi yang dikombinasikan dengan unit IPAL yang telah ada sebelumnya. Kualitas limbah hasil dari modifikasi unit IPAL industri tekstil untuk parameter COD, BOD, dan TSS masih belum memenuhi baku mutu serta masih berwarna pekat. Berdasarkan kinerja yang kurang baik, dibutuhkan solusi yang tepat untuk memperbaiki IPAL agar kualitas limbah yang dikeluarkan memenuhi baku mutu yaitu dengan melakukan evaluasi dari unit IPAL eksisting dan merencanakan desain alternatif baru yang efektif dan mampu memberikan keuntungan pada industri tekstil dari aspek teknis maupun aspek finansial untuk mengolah limbah yang dihasilkan.

Teknologi pengolahan air limbah terus berkembang seiring bertambahnya kebutuhan dan perubahan karakteristik air limbah yang lebih variatif. Perkembangan teknologi pengolahan limbah harus disesuaikan dengan kebutuhan dan daya dukung yang dimiliki oleh pihak industri. Salah satu alternatif teknologi pengolahan air limbah tekstil yang dapat digunakan adalah biofilter tercelup anaerobik-aerobik. Unit ini memiliki banyak keunggulan salah satunya adalah dengan kombinasi proses "anaerobik-aerobik" yang memiliki beberapa keunggulan seperti efisiensi penghilangan yang cukup besar untuk parameter yang diolah, energi yang digunakan untuk operasi lebih kecil sehingga biaya lebih murah, dan pengoperasian yang lebih mudah [1].

Evaluasi IPAL eksisting diharapkan bisa menganalisis unit IPAL yang berkinerja kurang baik dan dapat memberikan solusi apa yang harus dilakukan untuk memperbaikinya. Perencanaan ulang menggunakan alternatif biofilter tercelup anaerobik-aerobik diharapkan bisa menjadi solusi bagi industri tekstil ini untuk memperbaiki kinerja IPAL eksisting sehingga kualitas air baku yang dikeluarkan dapat memenuhi baku mutu dan terjadi keseimbangan dalam biaya operasi IPAL.

\section{METODOLOGI PERENCANAAN}

\section{A. Kerangka Perencanaan}

Kerangka perencanaan adalah sebuah diagram urutan dari setiap tahap yang dilakukan dalam evaluasi dan perencanaan ini. Kerangka perencanaan terdiri dari 8 tahap, yaitu: penentuan ide $\rightarrow$ survei lokasi $\rightarrow$ pengumpulan data $\rightarrow$ studi 
literatur $\rightarrow$ uji laboratorium $\rightarrow$ pengolahan dan analisis data $\rightarrow$ hasil dan pembahasan $\rightarrow$ kesimpulan dan saran.

\section{B. Kerangka Evaluasi}

Kerangka evaluasi adalah diagram alir yang digunakan untuk melakukan evaluasi IPAL eksisting. Kerangka evaluasi terdiri dari beberapa tahap, yaitu: melakukan pengukuran dan pengambilan sampel $\rightarrow$ menganalisis sistem IPAL dan menghitung data hasil uji laboratorium $\rightarrow$ melakukan pembangunan ulang semua unit sesuai kriteria desain atau memperbaiki unit yang bermasalah dan diikombinasikan dengan alternatif baru.

\section{GAMBARAN UMUM OBJEK PERENCANAAN}

IPAL terletak pada lahan seluas sekitar $\pm 300 \mathrm{~m}^{2}$. Sistem IPAL menggunakan kombinasi pengolahan kimiawi dan biologis. Unit yang dipakai dalam sistem saat ini secara berurutan adalah sebagai berikut: bak ekualisasi $\rightarrow$ bak koagulasi-flokulasi $\rightarrow$ bak pengendap flok $\rightarrow$ bak pengendapan final.

\section{HASIL DAN PEMBAHASAN}

\section{A. Perhitungan Debit IPAL}

Debit air limbah yang digunakan dalam perencanaan adalah debit yang dikeluarkan dari mesin pencelupan. Terdapat 6 buah unit mesin yang digunakan untuk proses pencelupan dan air sisa produksi dibuang langsung menuju IPAL. Setiap mesin memiliki kapasitas air yang berbeda. Debit yang dikeluarkan oleh tiap mesin beserta debit total yang masuk ke IPAL dapat dilihat pada Tabel 1.

Tabel 1.

Kapasitas Mesin dan Debit Air Limbah

\begin{tabular}{cccc}
\hline \hline Mesin & $\begin{array}{c}\text { Kapasitas mesin } \\
\text { (Liter air) }\end{array}$ & $\begin{array}{c}\text { Jumlah pemakaian } \\
\text { mesin } \\
\text { (maksimum) }\end{array}$ & $\begin{array}{c}\text { Total debit } \\
\text { (L/hari) }\end{array}$ \\
\hline 1 & 2.500 & 6 & 15.000 \\
2 & 3.000 & 6 & 18.000 \\
3 & 2.000 & 6 & 12.000 \\
4 & 2.000 & 6 & 12.000 \\
5 & 1.500 & 6 & 9.000 \\
6 & 2.500 & 6 & 15.000 \\
& Total & & 81.000 \\
\hline \hline
\end{tabular}

Sumber: Hasil Perhitungan dan Survei Lapangan

\section{B. Karakteristik Air Limbah IPAL}

Karakteristik air limbah yang digunakan dalam evaluasi dan perencanaan ulang adalah air limbah buangan proses produksi yang berasal dari mesin produksi. Hasil uji sampel digunakan sebagai data primer untuk menganalisis dan mengevaluasi serta perencanaan ulang menggunakan alternatif baru. Sampel diambil pada outlet mesin pencelupan kemudian diuji di laboratorium. Hasil uji laboratorium dapat dilihat pada Tabel 2.
Tabel 2.

Karakteristik Air Limbah IPAL Eksisting

\begin{tabular}{ccc}
\hline \multicolumn{3}{c}{ Karakteristik Air Limbah IPAL Eksisting } \\
\hline Parameter & Nilai & Satuan \\
\hline $\mathrm{pH}$ & 10,6 & - \\
$\mathrm{TSS}$ & 364 & $\mathrm{mg} / \mathrm{L}$ \\
Warna & 130 & $\mathrm{PtCo}$ \\
$\mathrm{COD}$ & 2.645 & $\mathrm{mg} / \mathrm{L}$ \\
BOD & 1.640 & $\mathrm{mg} / \mathrm{L}$ \\
\hline \hline
\end{tabular}

Sumber: Hasil Perhitungan

Hasil uji laboratorium menyimpulkan bahwa limbah yang dihasilkan kegiatan produksi bersifat basa, memiliki kadar COD, BOD, dan TSS yang tinggi.

\section{Analisis dan Evaluasi IPAL Eksisting}

Analisis dan evaluasi IPAL eksisting dilakukan dengan mengecek proses pengolahan dalam sistem IPAL eksisting dan mengukur dimensi eksisting tiap unit yang ada pada sistem pengolahan kemudian dibandingkan dengan kriteria desain dari tiap unit. Berikut adalah analisis dan evaluasi IPAL eksisting.

\section{1) Proses Sistem IPAL Eksisting}

Sistem pengolahan IPAL eksisting menggunakan sistem pengolahan yang terdiri dari kombinasi pengolahan fisik, kimiawi, dan biologis. Pembagian unit IPAL eksisting berdasarkan jenis pengolahannya adalah sebagai berikut:

a. Pengolahan Fisik

Unit pengolahan fisik meliputi:

- Menara pendingin (cooling tower)

- Bak pengendap lumpur

- Bak pengendap flok

- Bak pengendap final

b. Pengolahan Biologis meliputi unit tanki aerasi

c. Pengolahan kimiawi meliputi unit koagulasi-flokulasi dan netralisasi

Konsep pengolahan limbah yang baik adalah pengolahan yang dilakukan secara berurutan dari proses pengolahan primer yaitu proses fisik dan dilanjutkan dengan pengolahan tahap selanjutnya dengan proses biologis atau proses kimiawi maupun kombinasi. Hal ini disebabkan karena perbedaan kemampuan dari tiap unit dalam menghilangkan zat pencemar dalam air limbah [2].

Sistem IPAL eksisting sudah memiliki konsep pengolahan yang bagus tetapi air buangan IPAL masih memiliki permasalahan karena tidak urutnya unit dalam sistem pengolahan. Hal ini dapat diketahui dari diagram alir sistem pengolahan IPAL dimana setelah bak ekualisasi pengolahan langsung dilanjutkan ke pengolahan biologis menggunakan tanki aerasi dan bakteri tanpa ada pengolahan fisik untuk menurunkan parameter fisik limbah. Kinerja pengolahan biologis kurang maksimal karena beban yang masuk kedalam pengolahan biologis terlalu tinggi sehingga kurang efektif.

\section{2) Unit Bak Ekualisasi}

Bak ekualisasi adalah unit yang digunakan untuk menampung air limbah yang dibuang oleh mesin produksi dan menjaga kestabilan dari fluktuatifnya debit maupun konsentrasi yang masuk ke sistem IPAL [3]. Hasil perhitungan menunjukkan bahwa unit bak ekualisasi IPAL eksisting tidak 
sesuai dengan kriteria desain karena unit eksisting memiliki nilai waktu tinggal (td) lebih dari 4 jam yaitu sekitar 28,27 jam. Rekomendasi untuk bak ekualisasi adalah adanya perbaikan pada unit dengan membangun ulang berdasarkan hasil perhitungan yang telah sesuai dengan kriteria desain. Hasil evaluasi dan rekomendasi bak ekualisasi dapat dilihat pada Tabel 3 .

Tabel 3.

Hasil Evaluasi dan Rekomendasi Unit Bak Ekualisasi

\begin{tabular}{|c|c|c|c|c|}
\hline \multicolumn{2}{|c|}{ Dimensi Unit Eksisting } & $\begin{array}{l}\text { Kriteria } \\
\text { Desain }\end{array}$ & Keterangan & $\begin{array}{c}\text { Dimens } \\
\text { i Ideal }\end{array}$ \\
\hline Panjang bak & $=10,6 \mathrm{~m}$ & - & - & $5,2 \mathrm{~m}$ \\
\hline Lebar bak & $=5 \mathrm{~m}$ & - & - & $2,6 \mathrm{~m}$ \\
\hline Tinggi bak & $=2 \mathrm{~m}$ & $<4 \mathrm{~m}$ & sesuai & $2 \mathrm{~m}$ \\
\hline $\begin{array}{l}\text { Waktu } \\
\text { tinggal }\end{array}$ & $=\begin{array}{l}28,27 \\
\text { jam }\end{array}$ & $4-8$ jam & $\begin{array}{c}\text { tidak } \\
\text { sesuai }\end{array}$ & 8 jam \\
\hline
\end{tabular}

Sumber: Hasil Perhitungan

Tabel 3 menunjukkan bak ekualisasi IPAL eksisting tidak memenuhi kriteria desain karena memiliki waktu tinggal yang melebihi kriteria desain. Rekomendasi unit bak ekualisasi adalah melakukan pembongkaran dan dibangun ulang sesuai dengan dimensi ideal yang telah dihitung berdasarkan kriteria desain.

\section{3) Unit Bak Koagulasi - Flokulasi}

Bak koagulasi-flokulasi merupakan unit pengolahan kedua pada sistem IPAL eksisting yang digunakan saat ini untuk membentuk flok dari pencampuran dengan bahan koagulan. Koagulan yang digunakan pada tabung koagulasi adalah polymer Alumunium Chloride (PAC). Kemampuan PAC dalam meremoval parameter TSS, Warna, COD, dan BOD secara berurutan adalah sebesar 67,5\%; 75,5\%; 66\%; dan 83\% [4]. Hasil evaluasi unit dapat dilihat pada Tabel 4.

Tabel 4.

Hasil Evaluasi Unit Bak Koagulasi-Flokulasi

\begin{tabular}{lcccc}
\hline \hline \multicolumn{1}{c}{ Parameter } & $\begin{array}{c}\text { Unit } \\
\text { Eksisting }\end{array}$ & $\begin{array}{c}\text { Kriteria } \\
\text { Desain }\end{array}$ & Unit & Ket \\
\hline Waktu kontak & 35 & $30-45$ & menit & sesuai \\
Kec. Gradien (G) & 50 & $60-5$ & /detik & sesuai \\
Tahap flokulasi & 7 & $6-10$ & buah & sesuai \\
\hline \hline
\end{tabular}

Tabel 4 menunjukkan bahwa unit koagulasi-flokulasi memenuhi kriteria desain sehingga unit direkomendasikan untuk tetap digunakan.

\section{4) Unit Bak Pengendap Flok}

Bak pengendap flok adalah unit yang digunakan untuk mengendapkan flok dari proses flokulasi, Hasil perhitungan bak pengendap flok dapat dilihat pada Tabel 5 .

Tabel 5.

Hasil Evaluasi dan Rekomendasi Unit Bak Pengendap Flok

\begin{tabular}{lccc}
\hline \hline \multicolumn{2}{c}{ Dimensi Unit Eksisting } & Kriteria Desain & Keterangan \\
\hline $\mathrm{Td}$ & $=60 \mathrm{~s}$ & $40-60 \mathrm{~s}$ & Sesuai \\
Jarak sekat & $=17 \mathrm{~cm}$ & - & Tidak sesuai \\
Jumlah baffle & $=6 \mathrm{buah}$ & - & Tidak sesuai \\
\hline \hline \multicolumn{2}{l}{ Sumber: Hasil Perhitungan }
\end{tabular}

Tabel 5 menunjukkan bak pengendap flok tidak sesuai dengan kriteria desain. Rekomendasi untuk unit ini adalah dilakukan pembongkaran karena tidak sesuai dengan kriteria desain dan memiliki fungsi yang sama dengan bak pengendap final.

\section{5) Unit Bak Pengendap Final}

Hasil perhitungan dimensi unit bak pengendap final dapat disederhanakan dan dibandingkan dengan kriteria desain pada Tabel 6.

Tabel 6.

Hasil Evaluasi dan Rekomendasi Unit Bak Pengendap Final

\begin{tabular}{lccccc}
\hline \hline \multicolumn{3}{c}{ Dimensi Unit Eksisting } & Kriteria Desain & Ket & Dimensi Ideal \\
\hline Panjang Bak & $=$ & 6,6 meter & - & - & 2,9 \\
Lebar Bak & $=$ & 3,05 meter & - & - & 1,45 \\
Tinggi Bak & $=$ & 1,8 meter & $3-6$ & $\begin{array}{c}\text { Tida } \\
\mathrm{k}\end{array}$ & 3 \\
waktu & $=$ & $10,74 \mathrm{jam}$ & $1,5-2,5$ & $\begin{array}{c}\text { Tida } \\
\mathrm{k}\end{array}$ & 1,5 \\
tinggal & & & $\begin{array}{c}\text { Tida } \\
\mathrm{k}\end{array}$ & 1 \\
OFR & $=$ & $0,8-2,5$ & \\
& & & & \\
$\mathrm{~m}^{3} / \mathrm{m}^{2} \mathrm{jam}$ & & & &
\end{tabular}

Sumber: Hasil Perhitungan

Tabel 6 menunjukkan Bak pengendap final tidak sesuai dengan kriteria desain. Rekomendasi untuk unit adalah dilakukan pembongkaran dan dibangun sesuai dengan hasil perhitungan.

6) Kesetimbangan Massa

Kesetimbangan massa menggunakan persentase removal dari tiap unit dapat disederhanakan pada Tabel 7.

Tabel 7 menunjukkan persentase removal dari tiap unit sehingga dapat dihitung kadar pencemar yang dikeluarkan oleh IPAL industri tekstil $Z$. Hasil perhitungan dapat disederhanakan dalam Tabel 8.

Tabel 8.

Effluent IPAL Eksisting

\begin{tabular}{ccccc}
\hline \hline Parameter & Inlet & Outlet & Baku Mutu & Satuan \\
\hline TSS & 364 & 118,3 & 50 & $\mathrm{mg} / \mathrm{L}$ \\
Warna & 130 & 31,85 & - & $\mathrm{PtCo}$ \\
COD & 2.645 & 899,3 & 150 & $\mathrm{mg} / \mathrm{L}$ \\
BOD & 1.640 & 182,61 & 60 & $\mathrm{mg} / \mathrm{L}$ \\
\hline \hline
\end{tabular}

Sumber: Hasil Perhitungan

Tabel 8 menunjukkan bahwa IPAL eksisting menghasilkan limbah dengan effluent yang melebihi baku mutu, sehingga perlu dilakukan perencanaan ulang untuk memperbaiki kinerja agar limbah yang dihasilkan tidak melebihi baku mutu.

7) Rekomendasi Evaluasi

Hasil analisis dan evaluasi unit IPAL eksisting adalah semua unit tidak memenuhi kriteria desain dan untuk rekomendasi perbaikan ada beberapa opsi, yaitu:

a. Melakukan pembongkaran semua unit yang telah dievaluasi dan mengganti desain yang telah dihitung dengan kriteria desain dan menggunakannya sesuai dengan kondisi eksisting (unit dan sistem pengolahan tetap).

b. Melakukan pembongkaran terhadap unit IPAL eksisting yang telah dievaluasi dan membangun kembali unit dengan Dimendiimensi yang ideal serta mengganti unit tanki aerasi yang Ideal tidak dioperasikan dan mendapatkan keluhan dalam $40-60 \mathrm{~s}$
$28 \mathrm{~cm}$ 13 buannaerobik-aerobik yang dikombinasikan dengan unit adsoprsi karbon aktif.

\section{Perencanaan Ulang IPAL}

Perencanaan ulang adalah mendesain ulang dan mengganti beberapa unit eksisting sehingga memenuhi kriteria desain dan menghasilkan effluent yang sesuai dengan baku mutu. Perencanaan ulang ini memiliki beberapa alternatif untuk 
IPAL industri tekstil Z yaitu:

\section{1) Alternatif 1}

Alternatif satu pada perencanaan ulang ini adalah menggunakan urutan unit pengolahan sebagai berikut: Bak Ekualisasi $\rightarrow$ Bak Biofilter Tercelup Anaerobik-aerobik $\rightarrow$ Bak Koagulasi-flokulasi $\rightarrow$ Bak Pengendap Final $\rightarrow$ Karbon Aktif. Perhitungan dimensi dari unit biofilter adalah sebagai berikut mengacu pada kriteria desain dengan waktu tinggal 2428 jam; Rasio SS/COD=0,35-0,45; dan OLR $<4,5 \mathrm{~kg} / \mathrm{m}^{3}$.hari [5]. Perhitungan dari alternatif 1 adalah sebagai berikut:

a. Unit Bak Pengendap Awal

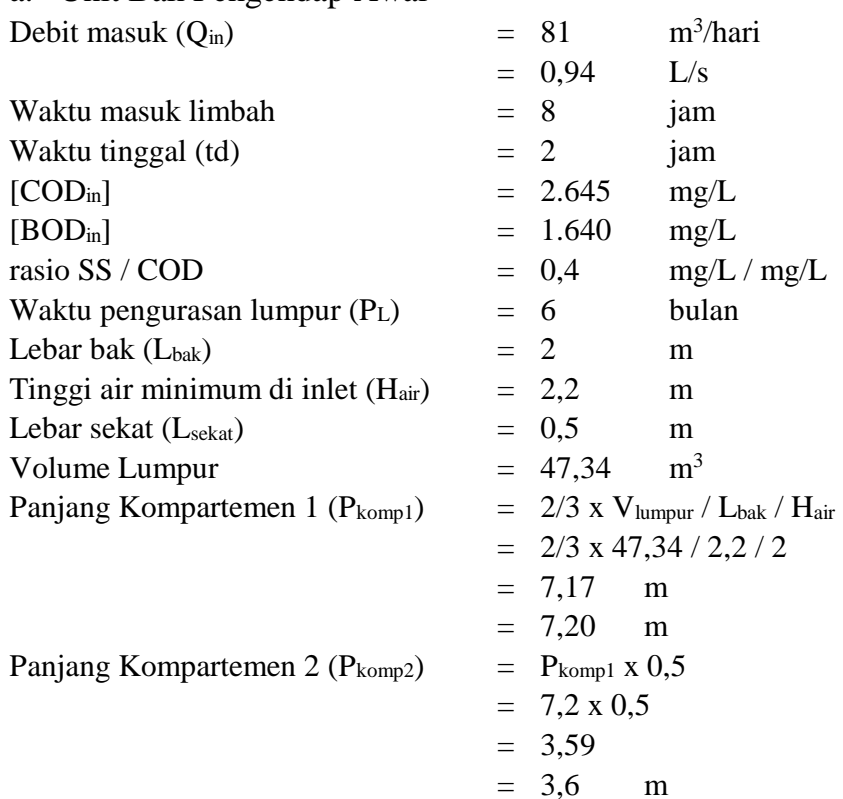

b. Unit Bak Anaerobik Biofilter

Debit puncak ( $\left.\mathrm{Q}_{\text {peak }}\right)$

$=\mathrm{Q}_{\text {in }} /$ tlimbah

$=81 / 8$

$=10,13 \quad \mathrm{~m}^{3} / \mathrm{jam}$

Volume Bak $\left(\mathrm{V}_{\text {bak }}\right) \quad=\quad \mathrm{Q}_{\text {in }} \mathrm{x}(\mathrm{HRT} / 24)$

$=81 \times(24 \times 24)$

$=81 \quad \mathrm{~m}^{3}$

Panjang bak $=\mathrm{V}_{\text {bak }} / \mathrm{n} /\left(\left(\mathrm{H}_{\text {air }} \mathrm{x} 0,25\right)+\left(\mathrm{L}_{\text {bak }} \mathrm{x}\left(\mathrm{H}_{\text {air }}-\mathrm{H}_{\text {filter }} \mathrm{X}\left(1-\mathrm{p}_{\mathrm{mf}}\right)\right)\right.\right.$

$=81 / 4 /((2,2 \times 0,25)+(2 \times(2,2-1,05 \times(1-0,98))$

$=4,13 \mathrm{~m}$

$=4,20 \mathrm{~m}$

Tinggi $\left(\mathrm{H}_{\text {filter }}\right)=\mathrm{H}_{\mathrm{air}}-\mathrm{L}_{\mathrm{cb}}-0.4-0.05$

$=2,2-0,5-0,4-0,05$

$=1,25 \mathrm{~m}$

Tinggi Bak $\left(\mathrm{H}_{\text {bak }}\right) \quad=\mathrm{H}_{\text {air }}+\mathrm{F}_{\mathrm{b}}$

$=2,2+0,3$

$$
=2,5 \quad \mathrm{~m}
$$

Luas Permukaan Bak $\left(\mathrm{A}_{\mathrm{s} 1}\right) \quad=$ Pkomp $\mathrm{x}$ Lbak

$$
=3,8 \times 2
$$$$
=8,40
$$

$\mathrm{m}^{2}$

Volume media filter $\left(\mathrm{V}_{\mathrm{mf}}\right)$

$$
=\mathrm{A}_{\mathrm{s}} \times \mathrm{H}_{\text {filter }}
$$$$
=8,4 \times 1,25
$$

\begin{tabular}{|c|c|c|}
\hline Debit puncak $\left(Q_{\text {peak }}\right)$ & $\begin{array}{l}=Q_{\text {in }} / \text { tlimbah } \\
=81 / 8 \\
=10,13\end{array}$ & $\mathrm{~m}^{3} / \mathrm{jam}$ \\
\hline \multirow[t]{2}{*}{ Volume Bak ( $V_{\text {bak }}$ ) } & $\begin{array}{l}=\quad \text { in } x(\text { HRT / 24) } \\
=81 \times(7 \times 24)\end{array}$ & \\
\hline & $=23,63$ & $\mathrm{~m}^{3}$ \\
\hline \multirow[t]{2}{*}{ Luas Permukaan Bak $\left(\mathrm{A}_{\mathrm{s} 1}\right)$} & $\begin{array}{l}=\mathrm{V}_{\text {bak }} / \mathrm{H}_{\text {air }} \\
=23,63 / 2,2\end{array}$ & \\
\hline & $=10,74$ & $\mathrm{~m}^{2}$ \\
\hline \multirow[t]{3}{*}{ Panjang kompartemen $\left(\mathrm{P}_{\text {komp }}\right)$} & $\begin{array}{l}=A_{s} / L_{b a k} \\
=10,74 / 2\end{array}$ & \\
\hline & $=5,37$ & $\mathrm{~m}$ \\
\hline & $=5,4$ & $\mathrm{~m}$ \\
\hline \multirow[t]{2}{*}{ Tinggi media filter $\left(\mathrm{H}_{\text {filter }}\right)$} & $\begin{array}{l}=\quad H_{\text {air }}-L_{c b}-0.4-0.05 \\
=\quad 2,2-0,5-0,4-0,05\end{array}$ & \\
\hline & $=1,25$ & $\mathrm{~m}$ \\
\hline \multirow[t]{3}{*}{ Tinggi Bak (Hak) } & $=\mathrm{H}_{\text {air }}+\mathrm{F}_{\mathrm{b}}$ & \\
\hline & $=2,2+0,3$ & \\
\hline & $=2,5$ & $\mathrm{~m}$ \\
\hline \multirow[t]{2}{*}{ Volume media filter $\left(\mathrm{V}_{\mathrm{mf}}\right)$} & $\begin{array}{l}=A_{s} \times H_{\text {filter }} \\
=10,74 \times 1,25\end{array}$ & \\
\hline & $=13,42$ & $\mathrm{~m}^{3}$ \\
\hline
\end{tabular}$$
=10,5
$$

$\mathrm{m}^{3}$ d. Unit Bak Pengendap Akhir

Debit masuk ( $\left(Q_{i n}\right) \quad=81$

Waktu masuk limbah $\quad=0,94 \quad \mathrm{~L} / \mathrm{s}$

Waktu tinggal (td) $\quad=2$ jam

Volume Bak $\left(\mathrm{V}_{\text {bak }}\right) \quad=(\mathrm{td} / 24) \times \mathrm{Q}_{\text {in }}$

$\begin{array}{rll} & =(2 / 24) \times 81 & \\ & =6,75 & \mathrm{~m} \\ \text { Lebar bak }\left(\mathrm{L}_{\text {bak }}\right) & =2 & \mathrm{~m} \\ \text { Tinggi air }\left(\mathrm{H}_{\text {air }}\right) & =2,2 & \mathrm{~m} \\ \text { Luas Permukaan Bak }\left(\mathrm{A}_{\mathrm{s} 1}\right) & =\mathrm{V}_{\text {bak }} / \mathrm{H}_{\text {air }} & \\ & =6,75 / 2,2 & \\ \text { Panjang bak (Pak) } & =3.07 & \mathrm{~m}^{2} \\ & =\mathrm{A}_{\mathrm{s} 1} / \mathrm{L}_{\text {bak }} & \\ & =3,07 / 2 & \mathrm{~m} \\ & =1,53 & \mathrm{~m}\end{array}$
Tabel 9.

Dimensi hasil perhitungan dapat disederhanakan pada

Tabel 9.

Dimensi Alternatif 1

\begin{tabular}{lcccc}
\hline \hline \multicolumn{1}{c}{ Parameter } & BP awal & Bak Anaerob & Bak Aerob & BP Akhir \\
\hline Panjang bak $(\mathrm{m})$ & $7,2 \& 3,6$ & 4,2 & 5,4 & 1,53 \\
Lebar bak $(\mathrm{m})$ & 2 & 2 & 2 & 2 \\
Tinggi Bak $(\mathrm{m})$ & 2,5 & 2,5 & 2,5 & 2,5 \\
Tinggi Media $(\mathrm{m})$ & - & 1,25 & 1,25 & - \\
\hline \hline
\end{tabular}

Sumber: Hasil Perhitungan

Unit pengolahan alternatif 1 dapat menghasilkan persentase removal yang dapat dilihat pada Tabel 10 .

c. Unit Bak Aerobik Biofilter 
Tabel 10 .

Persentase Removal Unit Alternatif 1

\begin{tabular}{lcccc}
\hline \multicolumn{1}{c}{ Unit } & \multicolumn{4}{c}{ Parameter } \\
& TSS & Warna & COD & BOD \\
\hline Bak Equalisasi & $0 \%$ & $0 \%$ & $0 \%$ & $0 \%$ \\
Bak Pengendapan Awal & $9,33 \%$ & $0 \%$ & $23,33 \%$ & $24,73 \%$ \\
Bak Anaerobik Biofilter & $55 \%$ & $45 \%$ & $45 \%$ & $45 \%$ \\
Bak Aerobik Biofilter & $25 \%$ & $25 \%$ & $35 \%$ & $35 \%$ \\
Bak Pengendapan & $9,33 \%$ & $0 \%$ & $23,33 \%$ & $24,73 \%$ \\
Biofilter & & & & \\
Koa-Flok & $67,5 \%$ & $75,5 \%$ & $66 \%$ & $83 \%$ \\
BP Final & $56 \%$ & $0 \%$ & $35 \%$ & $34,5 \%$ \\
Karbon Aktif & $0 \%$ & $80 \%$ & $0 \%$ & $0 \%$ \\
\hline \hline Sumber: Hasil Perhitungan & & & &
\end{tabular}

Persentase removal pada Tabel 10 dapat digunakan untuk menghitung kadar effluen dari alternatif 1 . Kadar effluen alternatif 1 dapat dilihat pada Tabel 11 .

Tabel 11.

Effluen Desain Alternatif

\begin{tabular}{|c|c|c|c|c|}
\hline Parameter & Inlet & Outlet & Baku Mutu & $\overline{\text { Satuan }}$ \\
\hline TSS & 364 & 11,95 & 50 & $\mathrm{mg} / \mathrm{L}$ \\
\hline Warna & 130 & 1,97 & - & PtCo \\
\hline COD & 2.645 & 104,14 & 150 & $\mathrm{mg} / \mathrm{L}$ \\
\hline $\mathrm{BOD}$ & 1.640 & 31,94 & 60 & $\mathrm{mg} / \mathrm{L}$ \\
\hline
\end{tabular}

Sumber: Hasil Perhitungan

Desain dari alternatif 1 dapat dilihat pada Gambar 1

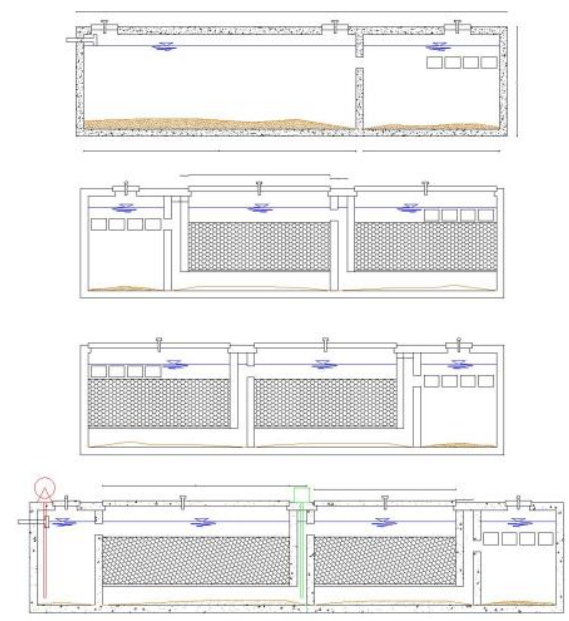

Gambar. 1. Desain Unit Biofilter Alternatif 1

\section{2) Alternatif 2}

Alternatif dua pada perencanaan ulang ini adalah menggunakan urutan unit pengolahan sebagai berikut: Bak Ekualisasi - Bak Koagulasi-flokulasi - Bak Biofilter Tercelup Anaerobik-aerobik - Bak Pengendap Final - Karbon Aktif. Dimensi hasil perhitungan terdapat pada Tabel 12. Tabel 12.

Effluen Desain Alternatif 2

\begin{tabular}{lcccc}
\hline \hline \multicolumn{1}{c}{ Parameter } & BP awal & Bak Anaerob & Bak Aerob & BP Akhir \\
\hline Panjang bak $(\mathrm{m})$ & $6,2 \& 3,1$ & 4,2 & 5,4 & 1,53 \\
Lebar bak $(\mathrm{m})$ & 2 & 2 & 2 & 2 \\
Tinggi Bak $(\mathrm{m})$ & 2,5 & 2,5 & 2,5 & 2,5 \\
Tinggi Media (m) & - & 1,25 & 1,25 & - \\
\hline \hline Sumber: Hasil Perhitungan & &
\end{tabular}

Unit pengolahan alternatif 2 dapat menghasilkan persentase removal yang dapat dilihat pada Tabel 13 .
Tabel 13

Persentase Removal Unit Alternatif 2

\begin{tabular}{lcccc}
\hline \multicolumn{1}{c}{ Unit } & \multicolumn{4}{c}{ Parameter } \\
& TSS & Warna & COD & BOD \\
\hline Bak Ekualisasi & $0 \%$ & $0 \%$ & $0 \%$ & $0 \%$ \\
Bak Koagulasi-Flokulasi & $67,5 \%$ & $75,5 \%$ & $66 \%$ & $83 \%$ \\
Bak Pengendapan Awal & $9,33 \%$ & $0 \%$ & $23,3 \%$ & $24,7 \%$ \\
Bak Anaerobik Biofilter & $55 \%$ & $45 \%$ & $45 \%$ & $45 \%$ \\
Bak Aerobik Biofilter & $25 \%$ & $25 \%$ & $35 \%$ & $35 \%$ \\
Bak Pengendapan Biofilter & $9,33 \%$ & $0 \%$ & $23,3 \%$ & $24,7 \%$ \\
Bak Pengendapan Final & $56 \%$ & $0 \%$ & $0 \%$ & $34,5 \%$ \\
Karbon Aktif & $0 \%$ & $80 \%$ & $0 \%$ & $0 \%$ \\
\hline \hline
\end{tabular}

Sumber: Hasil Perhitungan

Persentase removal pada Tabel 13 dapat digunakan untuk menghitung kadar effluen dari alternatif 2. Kadar effluen alternatif 2 dapat dilihat pada Tabel 14

Tabel 14.

Effluen Desain Alternatif 2

\begin{tabular}{ccccc}
\hline \hline Parameter & Inlet & Outlet & Baku Mutu & Satuan \\
\hline TSS & 364 & 15,93 & 50 & $\mathrm{mg} / \mathrm{L}$ \\
Warna & 130 & 6,33 & - & $\mathrm{PtCo}$ \\
COD & 2.645 & 29,05 & 150 & $\mathrm{mg} / \mathrm{L}$ \\
BOD & 1.640 & 2,99 & 60 & $\mathrm{mg} / \mathrm{L}$ \\
\hline \hline Sumber: Hasil Perhitungan & &
\end{tabular}

Desain alternatif 2 dapat dilihat pada Gambar 2.

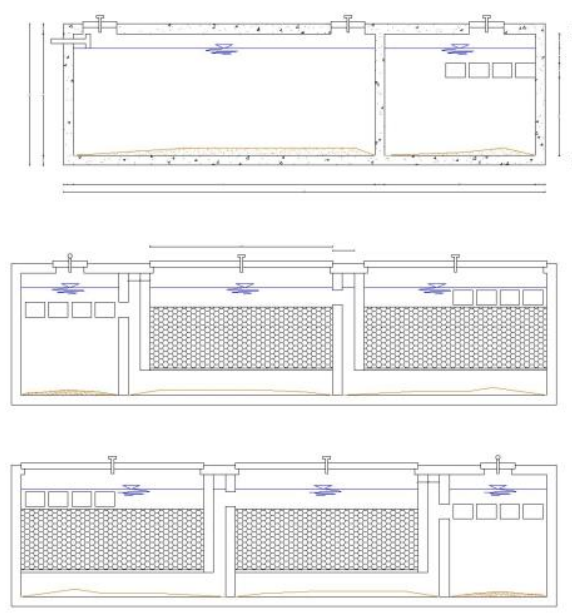

Gambar. 2. Desain Unit Biofilter Alternatif 2

\section{3) Alternatif 3}

Alternatif satu pada perencanaan ulang ini adalah menggunakan urutan unit pengolahan sebagai berikut: Bak Ekualisasi $\rightarrow$ Bak Biofilter Tercelup Anaerobik-aerobik $\rightarrow$ Bak Pengendap Final $\rightarrow$ Karbon Aktif. Dimensi hasil perhitungan terdapat pada memiliki hasil yang sama dengan desain alternatif 1 begitu juga dengan persentase removal yang dapat dilihat pada Tabel 15 . 
Tabel 15.

Effluen Desain Alternatif 3

\begin{tabular}{lcccc}
\hline \hline \multirow{1}{*}{ Unit } & \multicolumn{4}{c}{ Alternatif 1 } \\
& TSS & Warna & COD & BOD \\
\hline Bak Ekualisasi & $0 \%$ & $0 \%$ & $0 \%$ & $0 \%$ \\
BP Awal & $9,33 \%$ & $0 \%$ & $23,33 \%$ & $24,73 \%$ \\
Bak Anaerobik & $55 \%$ & $45 \%$ & $89,84 \%$ & $92,71 \%$ \\
Bak Aerobik & $25 \%$ & $25 \%$ & $58,53 \%$ & $60,29 \%$ \\
BP Akhir Biofilter & $0 \%$ & $0 \%$ & $0 \%$ & $0 \%$ \\
BP Final & $52,63 \%$ & $0 \%$ & $0 \%$ & $31,25 \%$ \\
Karbon Aktif & $0 \%$ & $80 \%$ & $0 \%$ & $0 \%$ \\
\hline \hline
\end{tabular}

Sumber: Hasil Perhitungan

\section{4) Unit Adsorpsi Karbon Aktif}

Karbon aktif digunakan untuk menurunkan kadar warna dalam air limbah bahan yang digunakan adalah arang kelapa. Karbon aktif yang diperlukan adalah sebesar 759,38 kg.

\section{E. Rancangan Anggaran Biaya}

Rancangan anggaran biaya dalam perencanaan ulang terdiri dari dua jenis yaitu biaya investasi dan biaya operasional. Biaya investasi adalah biaya yang diperlukan untuk membangun unit IPAL yang direncanakan. Biaya operasi adalah biaya yang dibutuhkan untuk menjalankan IPAL setelah dibangun. Rancangan Anggaran Biaya dari kedua alternatif desain yang terpilih dapat dilihat pada Tabel 13 .

Tabel 13 .

Rancangan Anggaran Biaya

\begin{tabular}{lll}
\hline \hline \multicolumn{1}{c}{ Unit } & \multicolumn{1}{c}{ Alternatif 1 } & \multicolumn{1}{c}{ Alternatif 2 } \\
\hline Bak Ekualisasi & Rp 88.512.430 & Rp 88.512.430 \\
Bak Pengendap Awal & Rp 82.314.539 & Rp 80.562.532 \\
Biofilter & Rp 506.748.015 & Rp 497.640.389 \\
Bak Pengendap Akhir & Rp 88.512.430 & Rp 88.512.430 \\
Adsorpsi & Rp 37.947.899 & Rp 37.947.899 \\
Diffuser & Rp 5.000.000 & Rp 5.000.000 \\
Filter Press & Rp 150.000.000 & Rp 150.000.000 \\
Total & Rp 804.035.312 & Rp 793.175.680 \\
\hline \hline
\end{tabular}

Sumber: Hasil Perhitungan

Biaya operasi dari perencanaan ulang terdiri dari biaya yang diperlukan untuk kegiatan operasi dan perawatan unit. Biaya operasi pada perencanaan ulang ini dapat dilihat pada Tabel 14.

\section{KESIMPULAN/RINGKASAN}

Kesimpulan dari evaluasi dan desain ulang adalah sebagai berikut:

a. Unit IPAL industri tekstil $\mathrm{Z}$ yang tidak berfungsi dengan baik adalah semua unit. Hal ini berdasarkan hasil perhitungan bahwa unit yang digunakan dalam sistem IPAL industri tekstil $\mathrm{Z}$ tidak sesuai dengan kriteria desain sehingga efektivitas dalam menghilangkan parameter pencemar tidak maksimal.

b. Limbah yang dihasilkan sistem IPAL industri tekstil $\mathrm{Z}$ dengan sistem IPAL eksisting tidak memenuhi baku mutu karena memiliki kadar TSS, COD, BOD, dan warna secara berurutan sebesar 52,05 mg/L; 899,3 mg/L; 182,61 mg/L; dan 31,85 PtCo. c. Rekomendasi dari hasil evaluasi adalah melakukan perencanaan ulang dengan mengganti unit tanki aerasi menggunakan unit biofilter tercelup anaerobik-aerobik karena tanki aerasi IPAL eksisting yang tidak dioperasikan dan mendapat keluhan kesulitan dalam pengoperasiannya.

d. Perencanaan ulang dibuat dengan tiga alternatif yaitu:

- Alternatif 1: Bak Ekualisasi- Bak Biofilter Tercelup Anaerobik-aerobik - Bak Koagulasi-Flokulasi - Bak Pengendap Final - Karbon Aktif

- Alternatif 2: Bak Ekualisasi - Bak Koagulasi-Flokulasi Bak Biofilter Tercelup Anaerobik-aerobik - Bak Pengendap Final - Karbon Aktif

- Alternatif 3: Bak Ekualisasi - Bak Biofilter Tercelup Anaerobik-aerobik - Bak Pengendap Final - Karbon Aktif

e. Limbah yang dihasilkan perencanaan ulang terpilih (alternatif 2) memiliki kadar TSS, COD, BOD, dan warna secara berurutan sebesar $15,93 \mathrm{mg} / \mathrm{L} ; 29,05 \mathrm{mg} / \mathrm{L} ; 2,99$ $\mathrm{mg} / \mathrm{L}$; dan 2,63 PtCo dengan biaya investasi sebesar Rp 793.175.680.

\section{UCAPAN TERIMA KASIH}

Penulis A.M. mengucapkan terima kasih kepada pihak industri yang telah memberikan kesempatan dan bantuan dalam melakukan evaluasi serta perencanaan ulang IPAL.

\section{DAFTAR PUSTAKA}

[1] Said, N. I. 2002. Teknologi Pengolahan Limbah Cair Dengan Proses Biologis. Jakarta: BPPT.

[2] von Sperling, M. and Chernicharo, C.A. 2005. Biological Wastewater Treatment in Warm Climate Regions Volume One. London: IWA Publishing.

[3] Metcalf and Eddy. 2004. Wastewater Engineering Treatment and Reuse $4^{\text {th }}$ Edition. Singapore: McGraw-Hill Company.

[4] Baraoidan, W. A., Tun, L. L., et al. 2007. A Study on the Relative Performance of Different Coagulant and the Kinetics of COD in the Treatment of a Textile Bleaching and Dyeing Industrial Wastewater. ASEAN Journal of Chemical Engineering, 7, pp. 49-60

[5] Sasse, L. 1998. DEWATS : Decentralised Wastewater Treatment in Developing Countries. Bremen: BORDA 